Research Article

\title{
Studying Disturbance Wave Velocity and Wall Shear Stress of Vertical Upward Annular Flow in Narrow Rectangular Channel
}

\author{
Antai Liu $\mathbb{D}^{1},{ }^{1}$ Changqi Yan, ${ }^{1}$ Fuqiang Zhu, ${ }^{1}$ Haifeng Gu $\mathbb{D}^{1},{ }^{1}$ and Suijun Gong ${ }^{2}$ \\ ${ }^{1}$ Heilongjiang Provincial Key Laboratory of Nuclear Power System \& Equipment, Harbin Engineering University, \\ Harbin 150001, China \\ ${ }^{2}$ Nuclear Power Institute of China, Chengdu 610005, China \\ Correspondence should be addressed to Antai Liu; antai_liu_v@163.com and Haifeng Gu; guhaifeng@hrbeu.edu.cn
}

Received 26 May 2021; Revised 9 July 2021; Accepted 13 August 2021; Published 30 August 2021

Academic Editor: Iztok Tiselj

Copyright (c) 2021 Antai Liu et al. This is an open access article distributed under the Creative Commons Attribution License, which permits unrestricted use, distribution, and reproduction in any medium, provided the original work is properly cited.

\begin{abstract}
As two important parameters, the velocity of disturbance wave and the wall shear stress in annular flow are very important to solve the closed equations of the mechanical model for annular flow. In this study, the disturbance wave velocity and wall shear stress of annular flow in a vertical narrow rectangular channel with a cross section of $70 \mathrm{~mm} \times 2 \mathrm{~mm}$ were studied. According to the experimental results, it is found that the wave velocity and wall shear stress of disturbance wave increase with increasing gas phase velocity and liquid phase velocity. Also, existing correlations for predicting the velocity of disturbance wave were summarized and evaluated using the current experimental data. A new correlation for wall shear stress based on the disturbance wave velocity has been proposed. Compared with the existing correlation for predicting wall shear stress, this new correlation can well predict the current experimental data and MAPE is only $7.32 \%$.
\end{abstract}

\section{Introduction}

As an important gas-liquid two-phase flow pattern, annular flow is common in modern industrial production processes. The annular flow is mainly composed of liquid film close to the tube wall, gas core, and liquid droplets in the gas core. The gas-liquid interface is not smooth and there are waves of different sizes. As an important part of the liquid film, these waves are usually associated with mass transfer and energy transfer. Disturbance wave is one of the key research points in annular flow and plays a leading role in the study of droplet entrainment and annular flow mechanical model. As one of the important physical parameters, the disturbance wave velocity is closely related to interfacial shear stress, wall shear stress, and pressure loss. Therefore, a great deal of research has been done on the properties of disturbance waves. Azzopardi [1] measured the disturbance wave velocity of annular flow in a vertical tube with an inner diameter of $31.8 \mathrm{~mm}$ by using the conductivity method. The experimental results show that the disturbance waves velocity increases with increasing gas phase velocity and liquid phase velocity. Kumar et al. [2] used the conductivity method to measure the disturbance wave velocity in a vertical rectangular channel with a cross-sectional area of $6.35 \times 63.5$. They assumed that the velocity of the wave was equal to the velocity of the interface and proposed a prediction correlation of the disturbance wave velocity. Schubring et al. [3] used high-speed photography technology to identify the disturbance wave based on the color of the liquid when the disturbance wave appears and calculated the speed of the disturbance wave according to the ratio of the distance traveled by the disturbance wave to the shooting time interval. Berna et al. [4] and Ju et al. [5] used published data and proposed a new correlation of disturbance wave velocity in their respective work. Wang et al. [6] proposed an improved disturbance wave velocity correlation in their work, which takes into account the influence of pressure. Ju et al. [7] deduced the relation between the disturbance wave velocity and the wall shear stress and fitted the correlation of the wall shear stress by using the public data. Lin et al. [8] studied the disturbance wave behavior of annular flow in a vertical circular pipe with an inner diameter of $20 \mathrm{~mm}$ by 
using high-speed camera and image processing technology. The effect of the onset of the disturbance wave was taken into account; they introduced the excess Reynolds number into the new prediction model of the disturbance wave velocity.

It can be seen from the literature survey that most of the research on the disturbance wave velocity is concentrated on the circular tube, but there is no research on the narrow rectangular channel. With the wide application of narrow rectangular channels in industrial production, such as compact heat exchangers and small reactors, it is necessary to study the disturbance wave velocity of annular flow in narrow rectangular channels.

In this paper, the disturbance wave in vertical annular flow is quantitatively visualized by high-speed video. And the disturbance wave velocity was measured and analyzed under the condition of normal temperature and atmospheric pressure.

\section{Experimental Facility and Method}

2.1. Experimental Apparatus. The schematic of the experimental system loop is shown in Figure 1(a); the experimental system was mainly composed of gas supply part and water supply part, a gas-liquid separation part, a test section, and a measurement system. The test section was made of acrylic material and feeler gauge, with a length of $2.3 \mathrm{~m}$ and a crosssectional area of $70 \mathrm{~mm}(\mathrm{~W}) \times 2 \mathrm{~mm}(\mathrm{H})$. The compressor feeds air into the test section through a mass flow meter. And water is pumped into the test section via a turbine flowmeter. The development rate of annular flow is related to the method of gas-liquid mixing. In order to accelerate the complete development of the annular flow, the design of the gas-liquid mixing section is shown in Figure 1(b). Water is injected from the side inlet at the bottom of the test section and flows into the flow channel through a $2 \mathrm{~mm}$ slit at the wide side of the narrow rectangular channel; air is injected from the wide side at the bottom of the test section. The air flow was measured by a DN15E $+\mathrm{H}$ Coriolis force mass flowmeter with the accuracy of $0.5 \%$, and the water flow was measured by a DN4 turbine flowmeter with the accuracy of $1 \%$.

In order to measure the velocity of disturbance wave, the images were digitally recorded by a high-speed video camera. A Photron-FASTCAM-SA5 high-speed camera with the SIGMA $105 \mathrm{~mm}$ lens was equipped for the flow visualization. In this paper, the shooting speed was set to be $5000 \mathrm{frames} / \mathrm{s}$. Additionally, the spatial resolution is $1024 \times 1024$ pixel. In order to ensure the full development of annular flow, the distance between the shooting position of high-speed photography and the mixing section is about $315 D$, where $D$ is equivalent diameter and defined as $D=4 A / P_{w}$. In addition, a PCB liquid film sensor was used to measure liquid film thickness, as shown in Figure 2. After calibration, the range of PCB liquid film sensor is $0-1 \mathrm{~mm}$. The distance between the PCB liquid film sensor and the gasliquid mixing section is about $210 \mathrm{D}$.

2.2. Experimental Procedure. The water is pumped into the test section at a small flow rate, and then the gas flow into the test section is adjusted until there was obvious gas slug. Later on, adjust the working condition to the annular flow according to the flow pattern diagram shown in Figure 3. The experimental flow conditions of this study were plotted on the upward gas-liquid flow pattern map in a vertical narrow rectangular channel proposed by Chalgeri [9]. In this study, the superficial liquid velocity ranges from 0.1 to $0.3 \mathrm{~m} / \mathrm{s}$ and superficial gas velocity from 30 to $66 \mathrm{~m} / \mathrm{s}$; it can be observed that the entire experiment corresponds to the annular flow condition in a vertical narrow rectangular channel.

2.3. Disturbance Wave Velocity Processing. Generally, the velocity is calculated by the ratio of the distance traveled by the disturbance wave to the time taken $[8,10]$. According to Schubring's works [3], the liquid becomes darker when disturbance waves appear. This paper adopts a calculation method similar to Schubring's works: a ruler was pasted on one side of the shooting area to calculate the distance traveled by the disturbance wave. The distance between the bottom of the ruler and the mixing section is about $288 \mathrm{D}$. Since the time interval between each frame is $0.2 \mathrm{~ms}$, the time difference used by the disturbance wave to pass the above distance is $\Delta t=0.2 \times\left(f_{\text {start }}-f_{\text {end }}\right)$, where $f_{\text {start }}$ is the frame number corresponding to the initial position of the disturbance wave and $f_{\text {end }}$ is the frame number corresponding to the final position of the disturbance wave. As discussed above, the velocity of a single disturbance wave can be calculated as follows:

$$
v_{\mathrm{DW}}=\frac{\Delta Z}{\Delta t},
$$

where $\Delta Z$ is the distance traveled by the disturbance wave and $\Delta t$ is time difference, as shown in Figure $4 . \Delta Z$ is measured by a ruler with MIN resolution of $1 \mathrm{~mm}$. Therefore, the maximum error of the calculation results according to equation (1) is $10 \%$.

\section{Results and Discussion}

3.1. Disturbance Wave Velocity. Through high-speed photography, it can be seen that the appearance of disturbance wave is accompanied by the change of liquid color. A huge disturbance wave can be observed, as shown in Figure 5. The huge disturbance waves propagate much faster than general disturbance waves. In addition, disturbance wave becomes more regular and uniform with increasing gas flow, and the huge waves are not obvious. However, the number of disturbance waves increases significantly and the regularity of disturbance waves becomes worse with the increasing liquid flow.

Disturbance wave velocity is a physical quantity with statistical properties, and its probability density is shown in Figure 6. It can be seen from these plots that the probability density image tends to shift to the right with increasing superficial gas velocity and superficial liquid velocity. In addition, it can be seen that there will be a bulge at the end of the probability density image in Figure 6(a), which is due to the high velocity of huge disturbance waves. In order to 


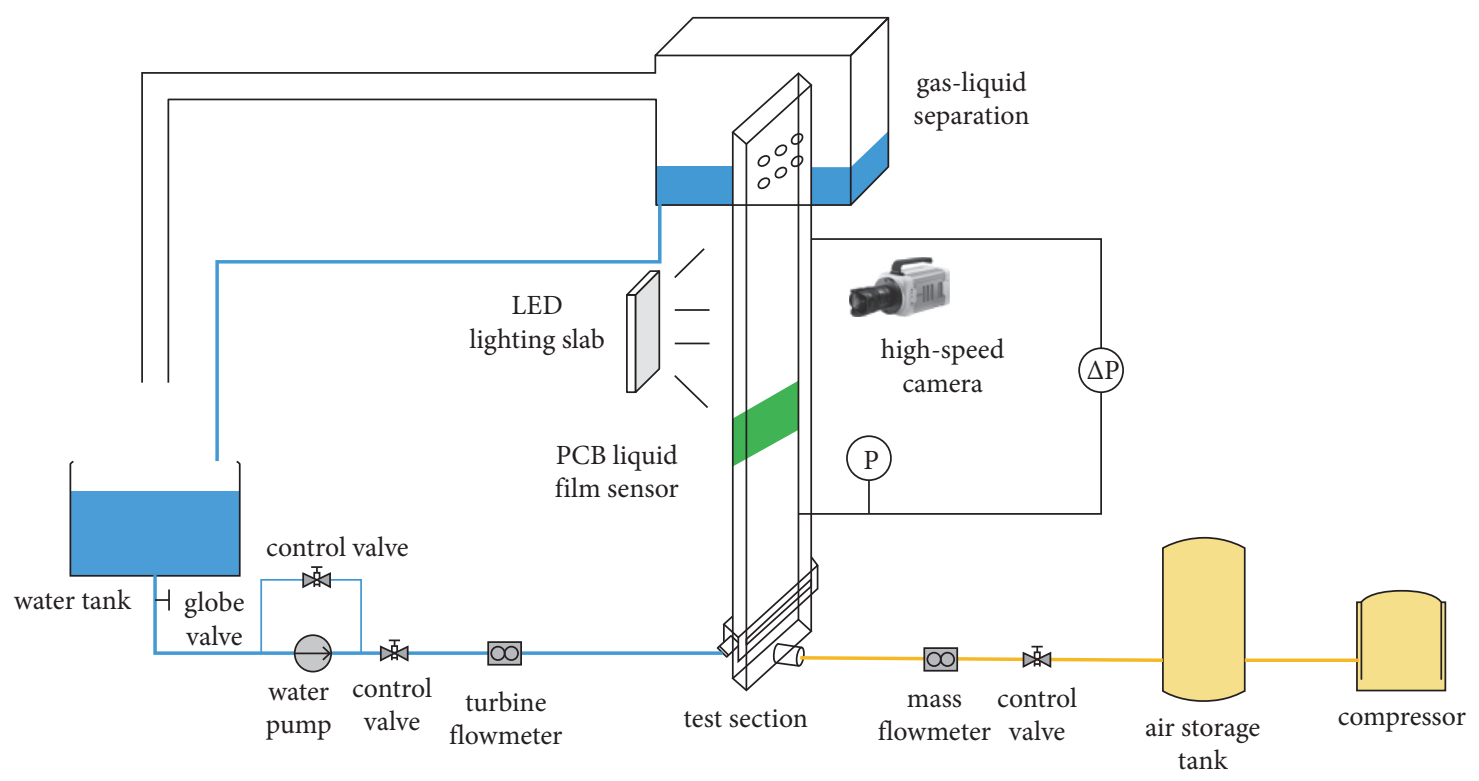

(a)
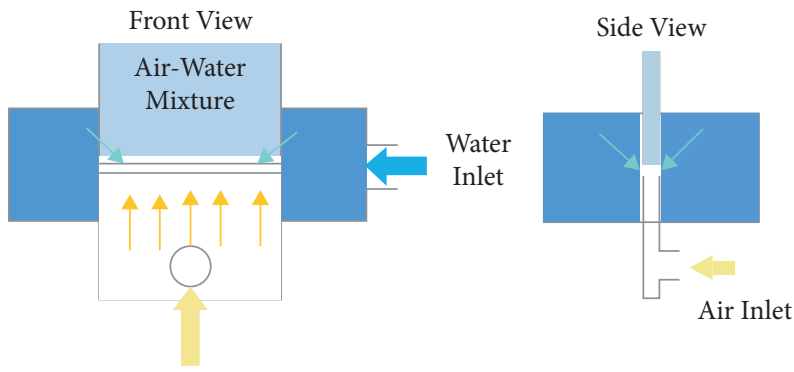

Air Inlet

(b)

Figure 1: Experimental facility. (a) Experimental system loop. (b) The gas-liquid mixing section.

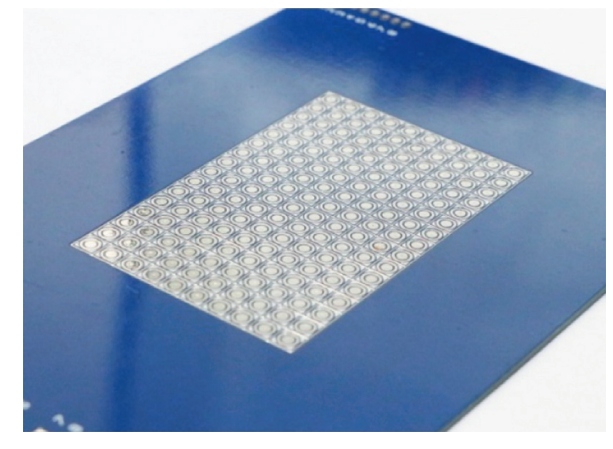

(a)

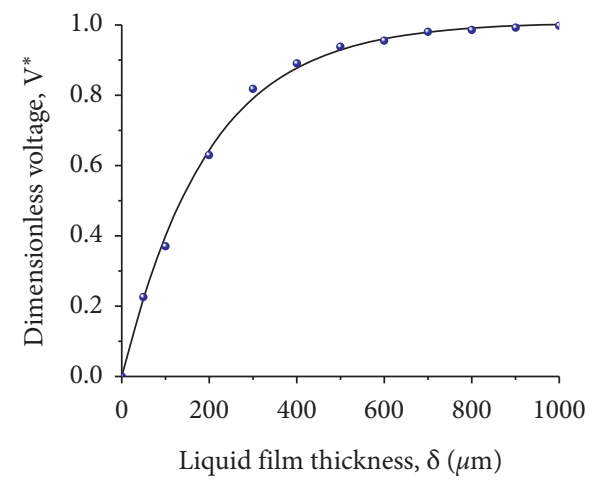

(b)

FIgure 2: PCB liquid film sensor. (a) Photograph of the PCB liquid film sensor. (b) Calibration curve of the liquid film sensor.

quantitatively analyze the influence of flow conditions on the disturbance waves velocity, the average wave velocity is used as the characteristic value of the disturbance wave velocity. Figure 7 shows the influence of flow conditions on the disturbance wave velocity. It can be seen from the figure that the disturbance wave velocity increases with increasing gas phase velocity and liquid phase velocity. This is reasonable because the driving force of the disturbance wave comes from the interface friction between the gas and liquid phase; the increase of gas phase velocity strengthens the driving force of the disturbance wave, which leads to the increase of wave velocity. On the other hand, the liquid film becomes thicker 


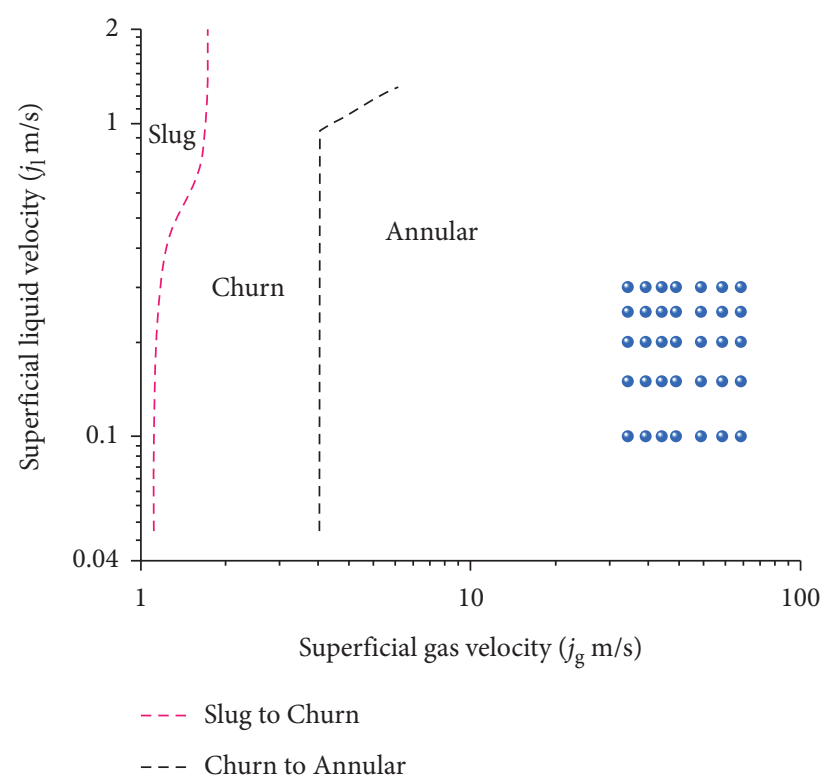

FIgURE 3: Experimental conditions on the flow pattern map of Chalgeri (Chalgeri et al., 2019).

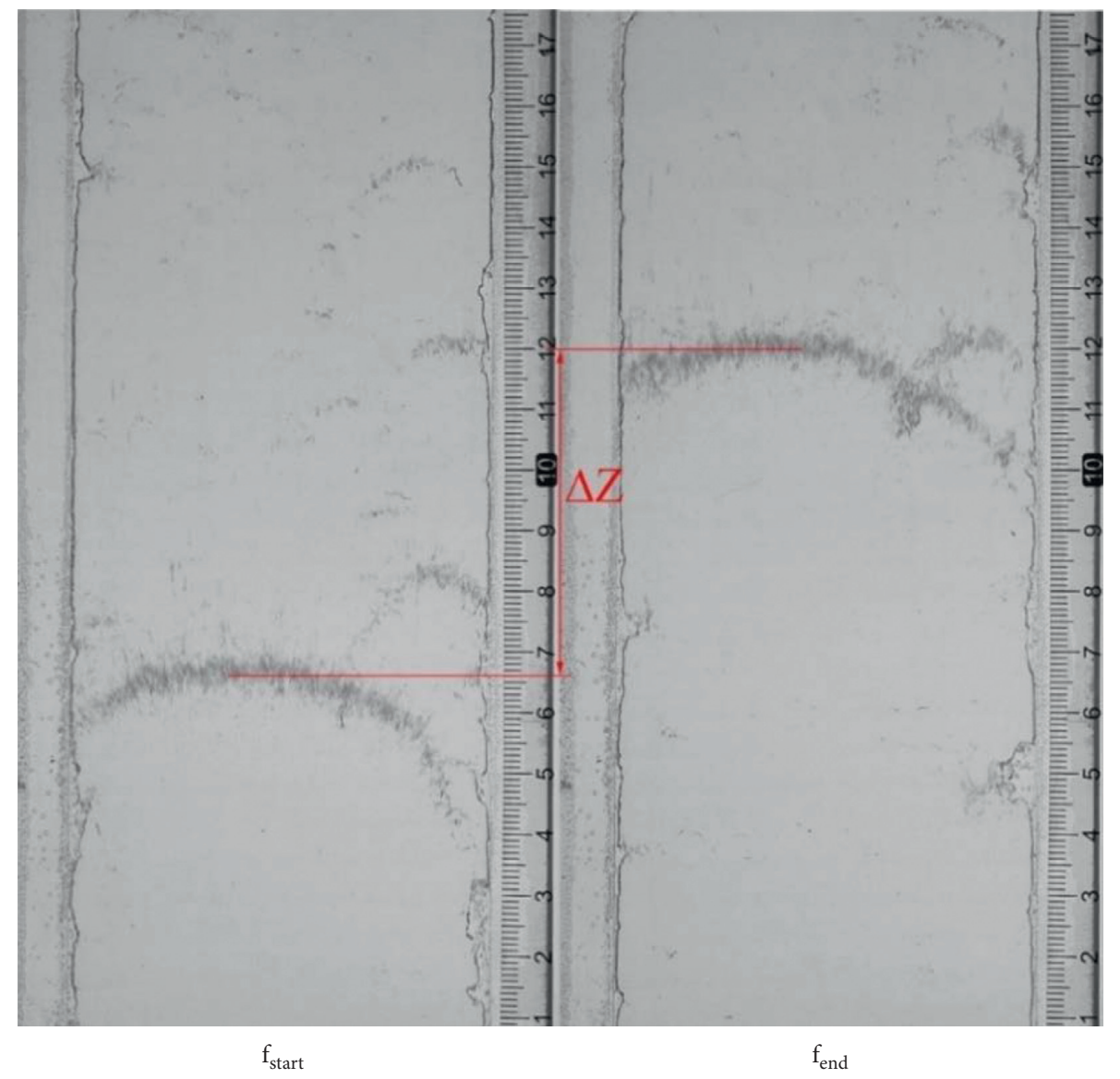

FIGURE 4: Disturbance wave example images $\left(j_{g}=30 \mathrm{~m} / \mathrm{s}, j_{l}=0.1 \mathrm{~m} / \mathrm{s}\right)$.

with increasing liquid flow rate, which promotes the formation of disturbance waves. Moreover, the thicker liquid film increases the distance between the disturbance wave and the wall surface, so that the influence of the wall surface on the disturbance wave is reduced. Similar physical phenomenon can be seen in the works of Schubring [11] and Alamu [12].

The existing prediction correlations of the disturbance wave velocity are summarized in Table 1 . These correlations 


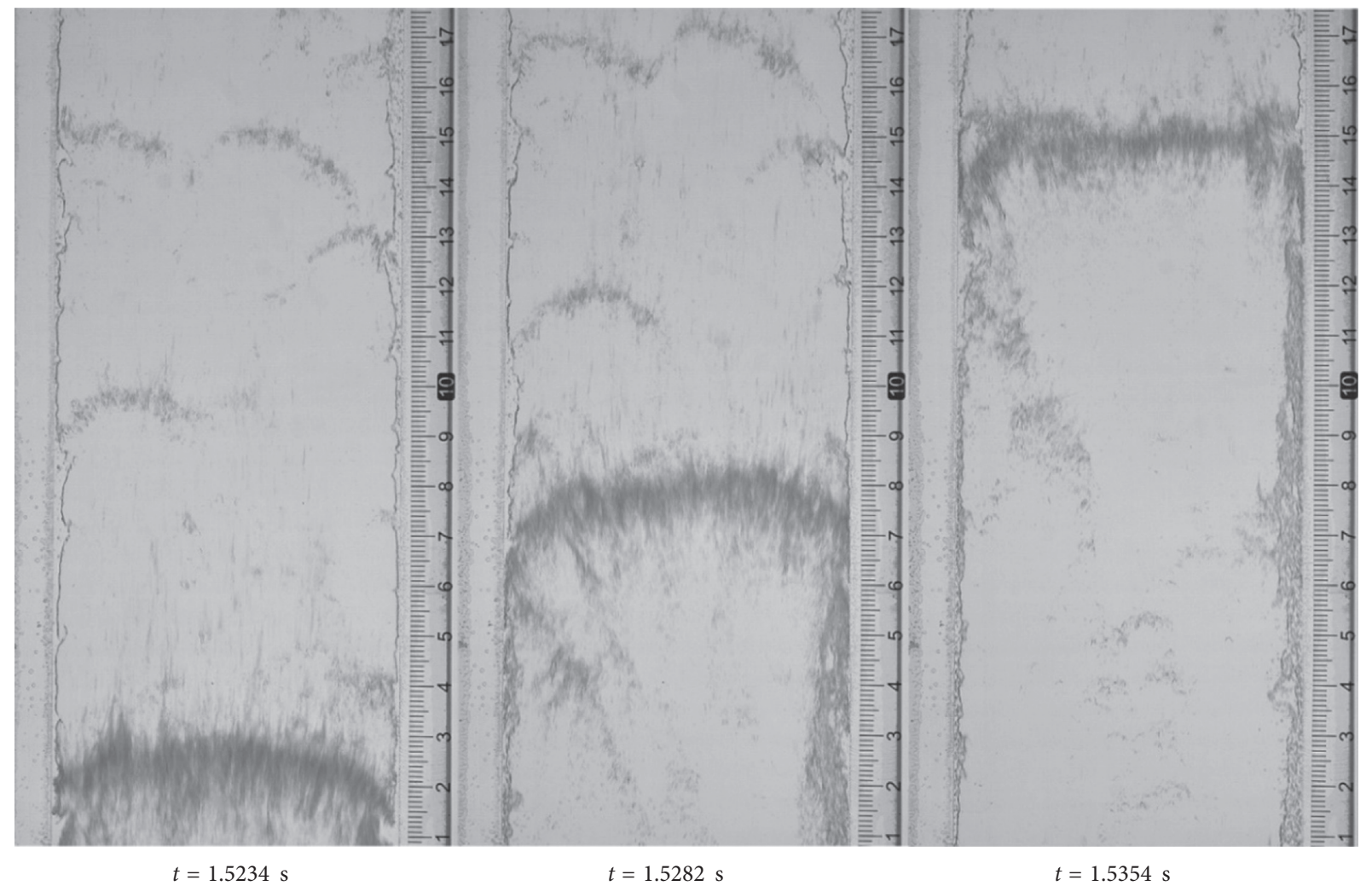

Figure 5: Huge disturbance wave $\left(j_{g}=30 \mathrm{~m} / \mathrm{s}, j_{l}=0.3 \mathrm{~m} / \mathrm{s}\right)$.

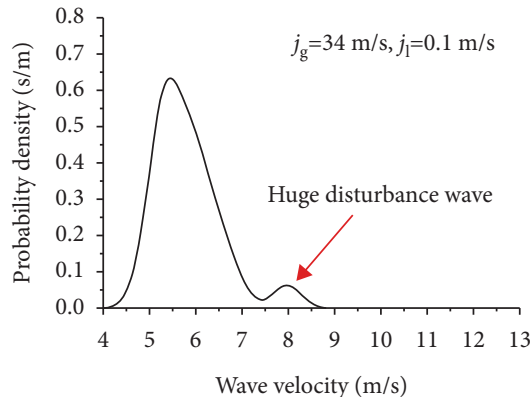

(a)

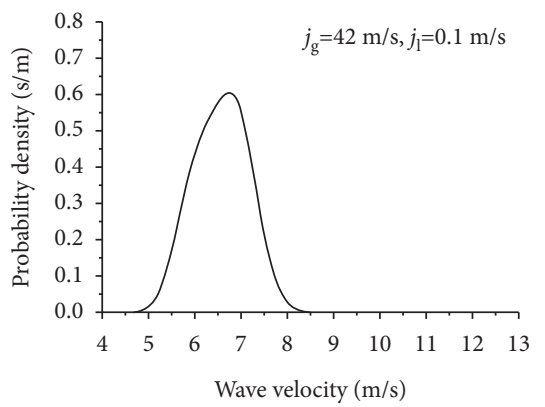

(d)

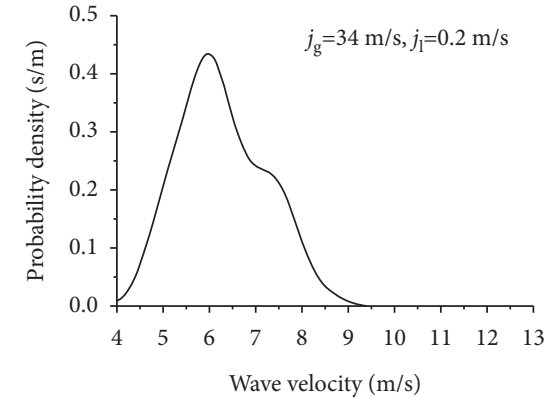

(b)

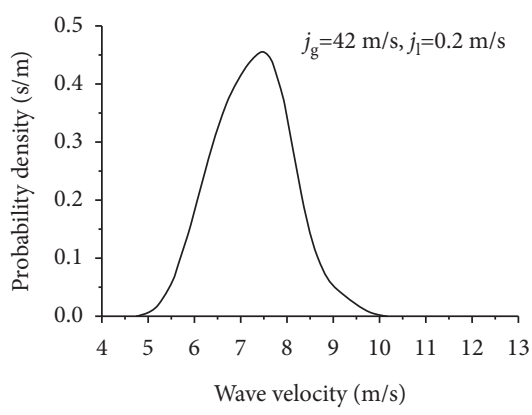

(e)

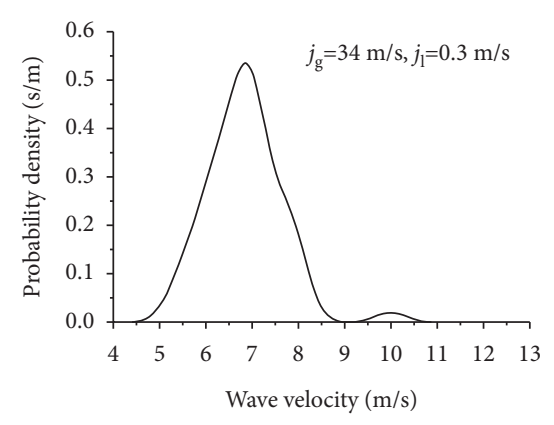

(c)

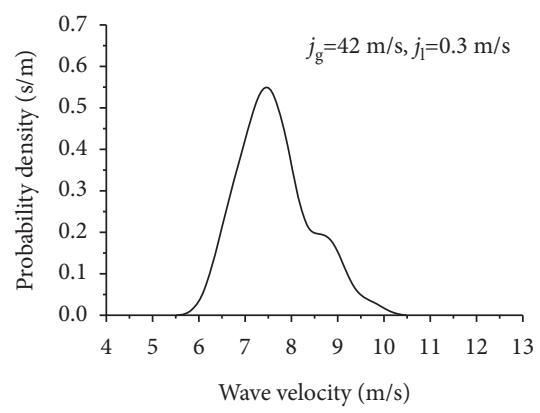

(f)

FIgure 6: Continued. 


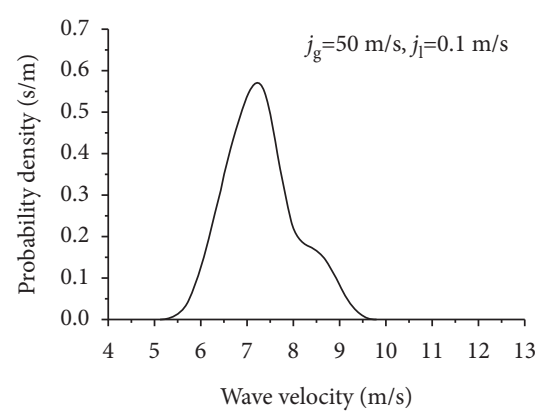

(g)

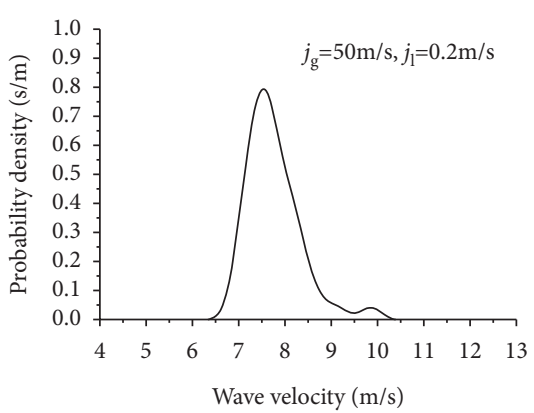

(h)

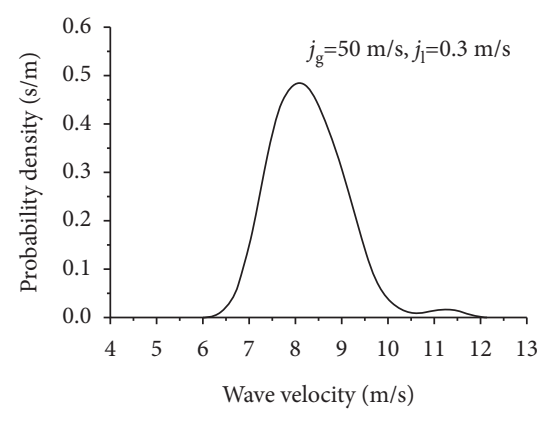

(i)

FIGURE 6: Probability density plots of wave velocity for various combinations of air and water flow rates.

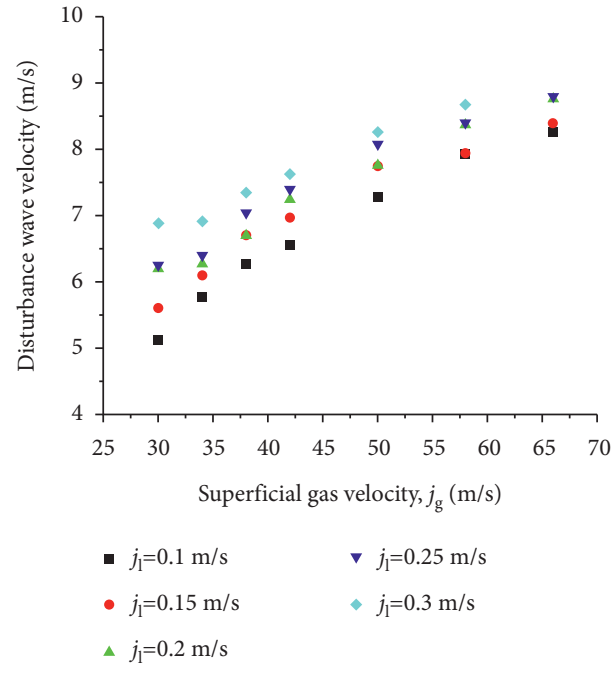

(a)

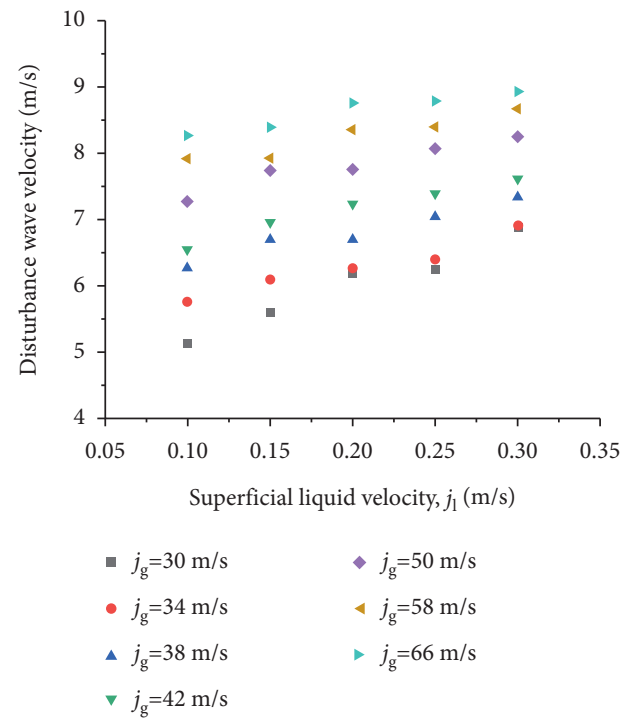

(b)

Figure 7: Influence of flow condition on disturbance wave velocity. (a) Effect of superficial gas velocity. (b) Effect of superficial liquid velocity.

were evaluated using current data, and the results are shown in Figure 8. It can be seen from the figure that the predicted results of Ju et al. correlation [5] are close to the experimental value, and the predicted results are closer to the experimental value with increasing superficial liquid velocity. In order to quantify and compare the prediction errors of each prediction correlation, the relative error between correlation predicted results and experimental value is shown in Figure 9. The predicted results of the Ju Peng's correlation were all within the $20 \%$ error range and MAPE is only $10.03 \%$, so the correlation of Ju et al. [5] can better predict the velocity of the disturbance wave in this experiment.

3.2. Wall Shear Stress. According to derivation of the mechanical equation of the vertical upward annular flow [15], the wall shear stress can be expressed by the following equation:

$$
\tau_{w} P_{w}=\tau_{i} P_{c}-\left(\frac{\mathrm{d} p}{\mathrm{~d} z}+\rho_{l} g\right)\left(A-A_{c}\right)+P_{c}\left(e_{d} v_{d}-e v_{e}\right)
$$

where $\tau_{i}$ is the interfacial shear stress, $P_{c}$ is gas core perimeter, $e$ is entrainment rate, $e_{d}$ is deposition rate, $v_{d}$ is droplet deposition velocity, and $v_{e}$ is droplet entrainment velocity. Based on the derivation of Wongwises [16], the equation of interfacial shear stress in the annular flow under equilibrium state can be written in the following form:

$\tau_{i}=e v_{e}-e_{d} v_{d}-\frac{1}{P_{c}}\left[A_{c}\left(1-\frac{\rho_{c} v_{g}^{2}}{p}\right) \frac{\mathrm{d} p}{\mathrm{~d} z}+v_{g} \frac{\mathrm{d} \dot{m}_{e}}{\mathrm{~d} z}+\rho_{c} A_{c} g\right]$.

Because the annular flow is fully developed, it is assumed that deposition and entrainment rates are equal and entrainment mass flow rate is constant, as well as the gas non- 
TABLE 1: Summary of correlations for the disturbance wave velocity.

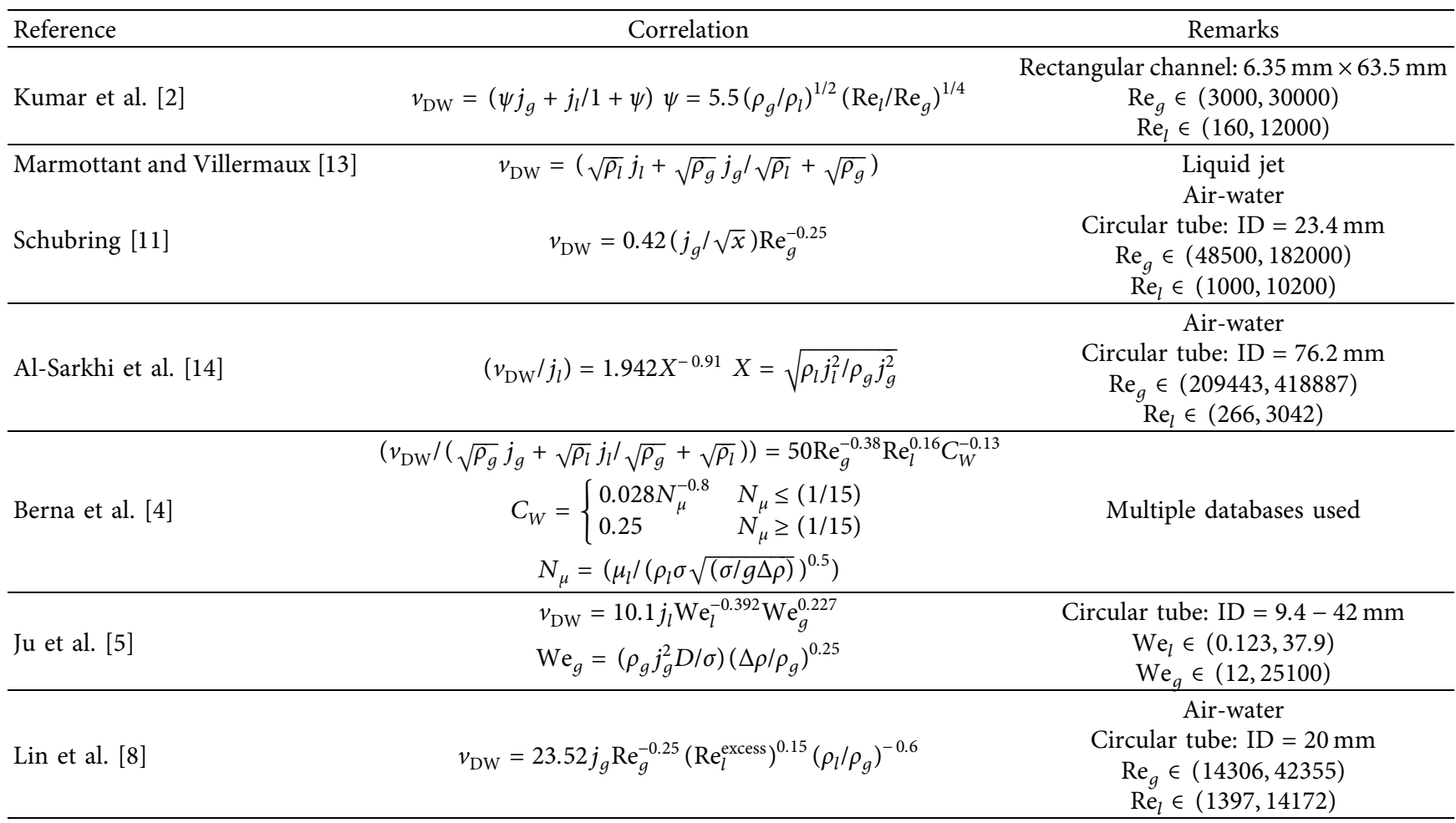

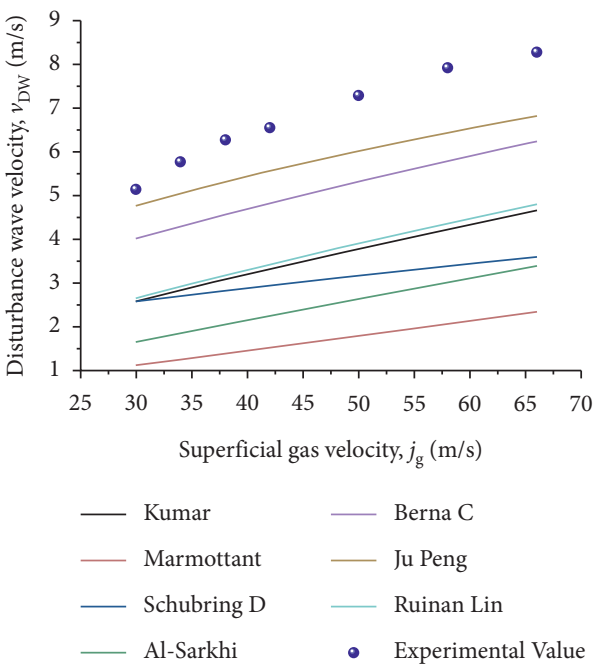

(a)

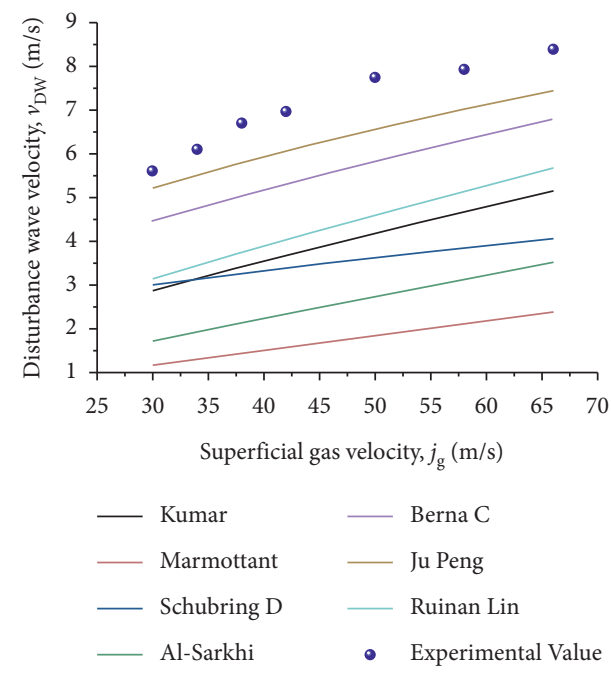

(b)

Figure 8: Continued. 


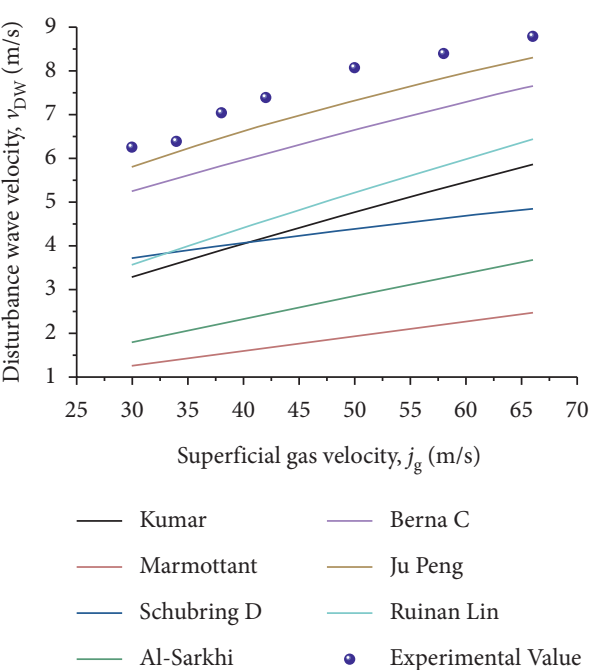

(c)

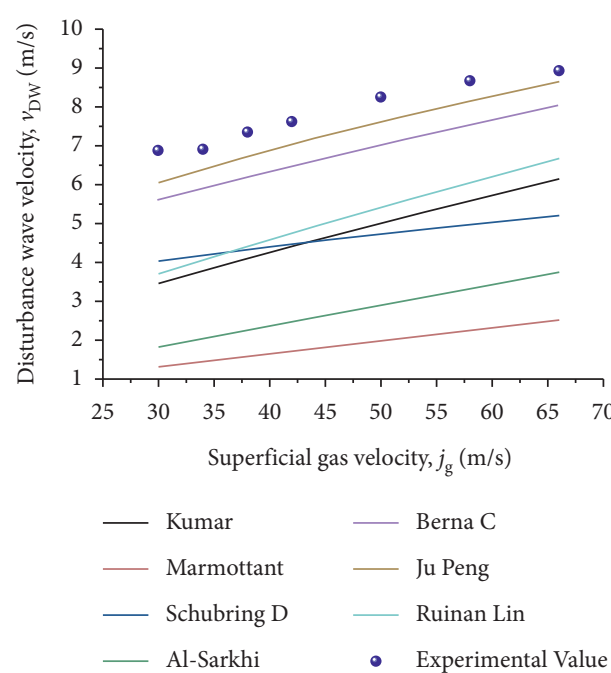

(d)

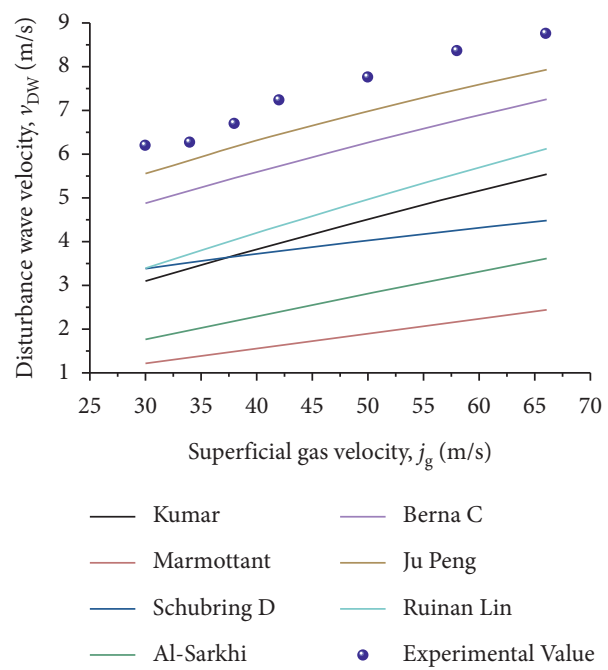

(e)

FIGURE 8: Comparison of mean liquid film thickness by various correlations with present experimental data. (a) $j_{1}=0.1 \mathrm{~m} / \mathrm{s}$. (b) $j_{1}=0.15 \mathrm{~m} / \mathrm{s}$. (c) $j_{1}=0.2 \mathrm{~m} / \mathrm{s}$. (d) $j_{1}=0.25 \mathrm{~m} / \mathrm{s}$. (e) $j_{1}=0.3 \mathrm{~m} / \mathrm{s}$.

expansion. Combining equations (2) and (3), the wall shear stress can be simplified as

$$
\tau_{w} P_{w}=A_{c}\left(-\frac{\mathrm{d} p}{\mathrm{~d} z}-\rho_{c} g\right)-\left(\frac{\mathrm{d} p}{\mathrm{~d} z}+\rho_{l} g\right)\left(A-A_{c}\right),
$$

where $\tau_{w}$ is the wall shear stress, $P_{w}$ is the wall wetted perimeter, $A$ is the pipe cross-sectional area, $A_{c}$ is the gas core cross-sectional area, $\mathrm{d} p / \mathrm{d} z$ is the measured pressure gradient, $g$ is the acceleration of gravity, $\rho_{l}$ is the liquid density, and $\rho_{c}$ is the gas core density and calculated by correlation proposed by Cioncolini [17]:

$$
\begin{aligned}
\rho_{c} & =\frac{x+e(1-x)}{\left(x / \rho_{g}\right)+\left(e(1-x) / \rho_{l}\right)}, \\
\mathrm{We}_{c} & =\frac{\rho_{c} j_{g}^{2} D}{\sigma},
\end{aligned}
$$

$$
e=\left(1+279.6 \mathrm{We}_{c}^{-0.8395}\right)^{-2.209},
$$

where $\mathrm{We}_{c}$ is core flow Weber number and $x$ is the mass gas quality and can be calculated as

$$
x=\frac{\rho_{g} j_{g}}{\rho_{g} j_{g}+\rho_{l} j_{l}} .
$$

Equations (5) and (6) are not independent, so iterative solutions are needed; i.e., let $\rho_{c}$ be equal to $\rho_{g}$ to calculate $e^{n}$; then use $e^{n}$ to calculate $e^{n+1}, n=1,2,3, \ldots$, until $\left|e^{n+1}-e^{n}\right|<10^{-8}$.

It can be seen from equation (4) that the cross-sectional area of the gas core is needed to calculate the wall shear stress; the gas core area is defined as

$$
A_{c}=\left(W-2 \delta_{m}\right)\left(H-2 \delta_{m}\right)
$$




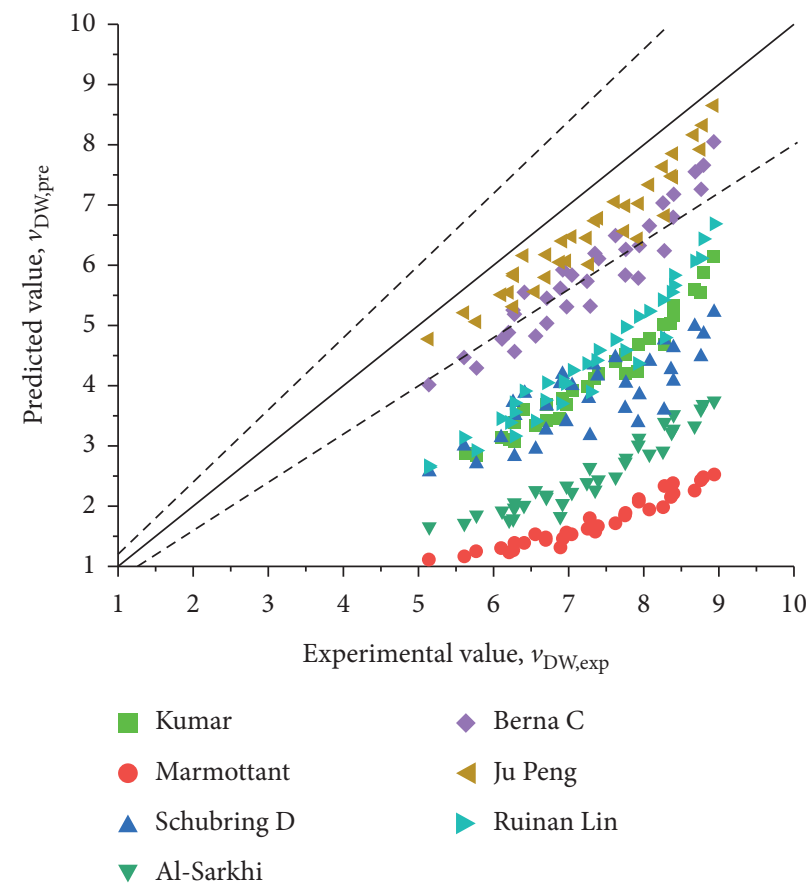

FIGURE 9: Disturbance wave velocity relative error between correlation predicted results and experimental value.

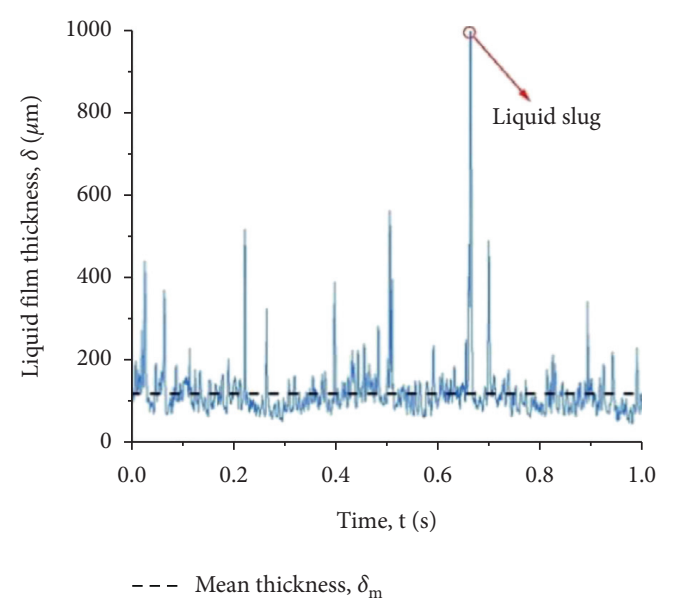

(a)

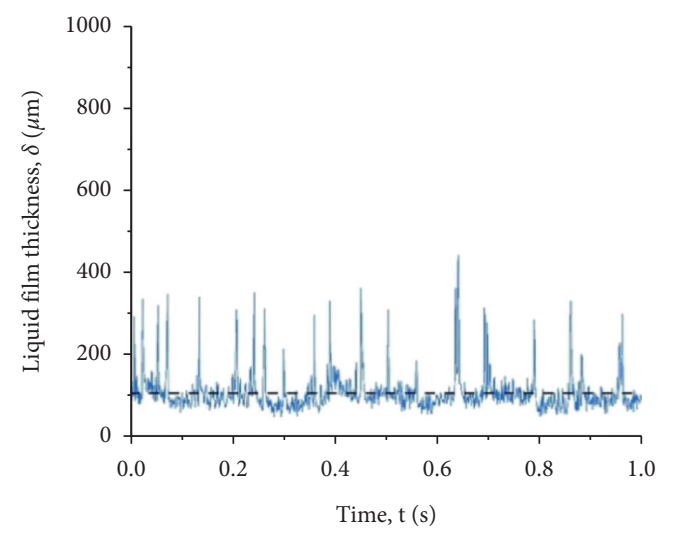

- - - Mean thickness, $\delta_{\mathrm{m}}$

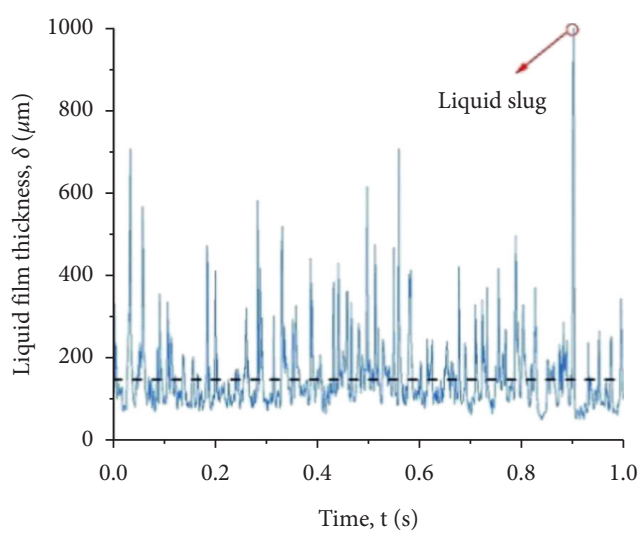

- - - Mean thickness, $\delta_{\mathrm{m}}$

(b)

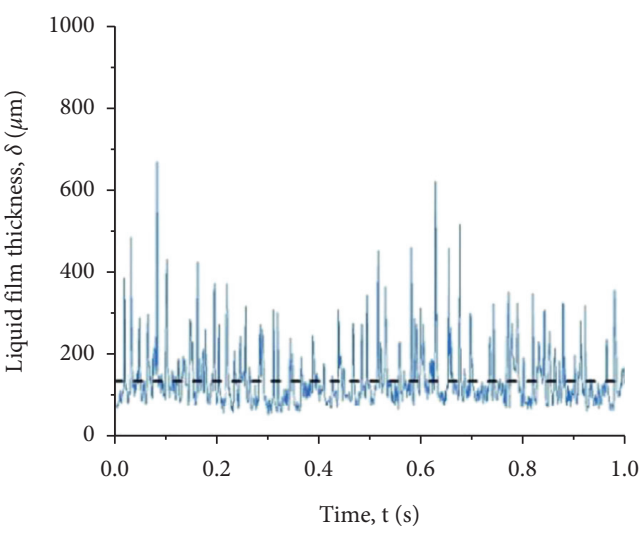

- - Mean thickness, $\delta_{\mathrm{m}}$

(c)

(d)

Figure 10: Continued. 


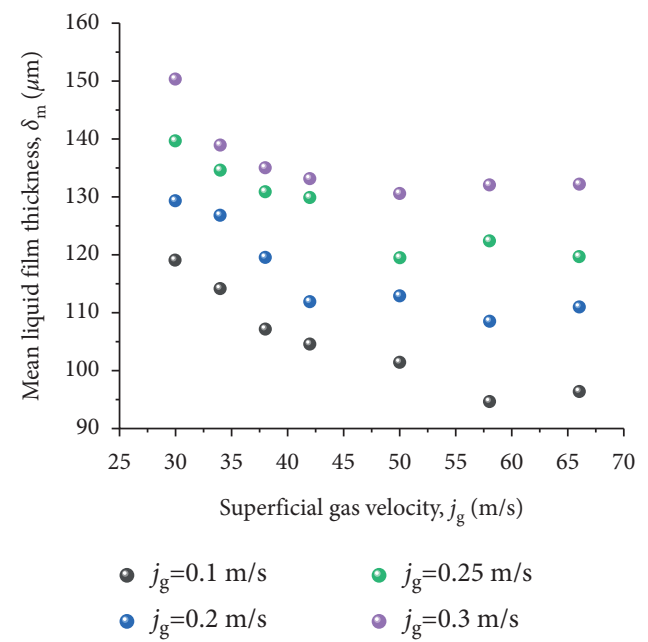

(e)

FIgURE 10: Variation of liquid film thickness with flow conditions. (a) $j_{g}=30 \mathrm{~m} / \mathrm{s}, j_{l}=0.1 \mathrm{~m} / \mathrm{s}$. (b) $j_{g}=30 \mathrm{~m} / \mathrm{s}, j_{l}=0.3 \mathrm{~m} / \mathrm{s}$. (c) $j_{g}=38 \mathrm{~m} / \mathrm{s}, j_{l}=0.1 \mathrm{~m} / \mathrm{s}$. (d) $j_{g}=38 \mathrm{~m} / \mathrm{s}, j_{l}=0.3 \mathrm{~m} / \mathrm{s}$. (e) Mean liquid film thickness.

where $\delta_{m}$ is mean liquid film thickness and obtained by the PCB liquid film sensor. Figures $10(a)-10(d)$ show the variation of liquid film thickness in time domain; it can be seen from the figures that the liquid film becomes thicker and the number of wave crests also increases significantly with increasing liquid flow rate. In addition, the peak with an amplitude of $1 \mathrm{~mm}$ indicates the presence of a local liquid plug in the channel; i.e., the liquid films on opposite walls are connected together. Figure 10(e) shows the variation of average liquid film thickness with flow conditions. It can be seen that the average liquid film thickness increases with increasing liquid phase velocity and decreases with increasing gas phase velocity. Moreover, the change of liquid film thickness tends to be gentle with the further increase of gas phase velocity.

According to the above analysis, the calculation results of wall shear stress in this paper are shown in Figure 11. It can be seen from the figure that the wall shear stress increases with the increase of gas and liquid velocity. According to previous studies, wall shear stress can be related to the velocity of disturbance wave. Swanson [18] found that the product of the gas density and the square of the disturbance wave velocity is proportional to the wall shear stress:

$$
\tau_{w}=\rho_{g} v_{\mathrm{DW}}^{2} .
$$

Ju et al. [7] assumed that the disturbance wave velocity was equal to twice the liquid film velocity and derived the relationship between the wall shear stress and the disturbance wave velocity, and fitted the formula coefficients based on the published data:

$$
\tau_{w}=0.00153 \rho_{l} v_{\mathrm{DW}}^{2}
$$

In addition, Schubring and Shedd [19] proposed an empirical correlation for wall shear stress of air-water twophase annular flow based on the experimental results under normal temperature and pressure:

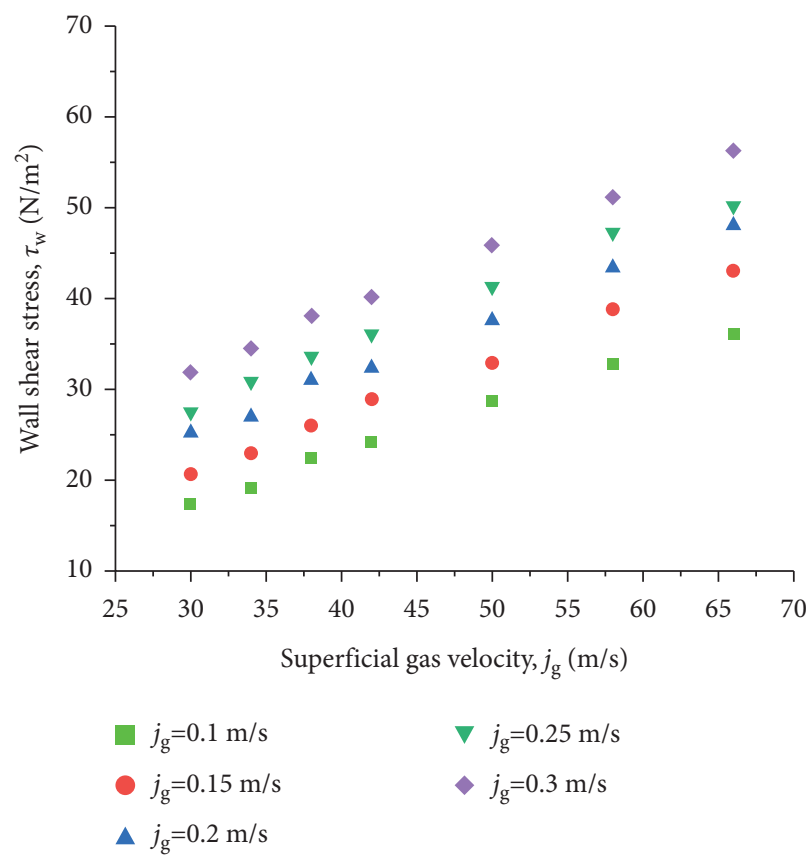

FIGURE 11: Variation of wall shear stress with flow conditions.

$$
\tau_{w}=0.0217 \frac{0.5 \rho_{g} j_{g}^{2}}{x} \operatorname{Re}_{G}^{-0.15},
$$

where $\operatorname{Re}_{G}=\left(\left(\rho_{g} j_{g}+\rho_{l} j_{l}\right) D / \mu_{l}\right)$ is the modified Reynolds number.

It can be seen from Figure 12 that there is a large deviation between the predicted results of the above correlation and the current experimental data. Schubring's correlation can predict the wall shear stress at low gas phase flow rate, but the deviation between the predicted value and the experimental data increases gradually with increasing gas 


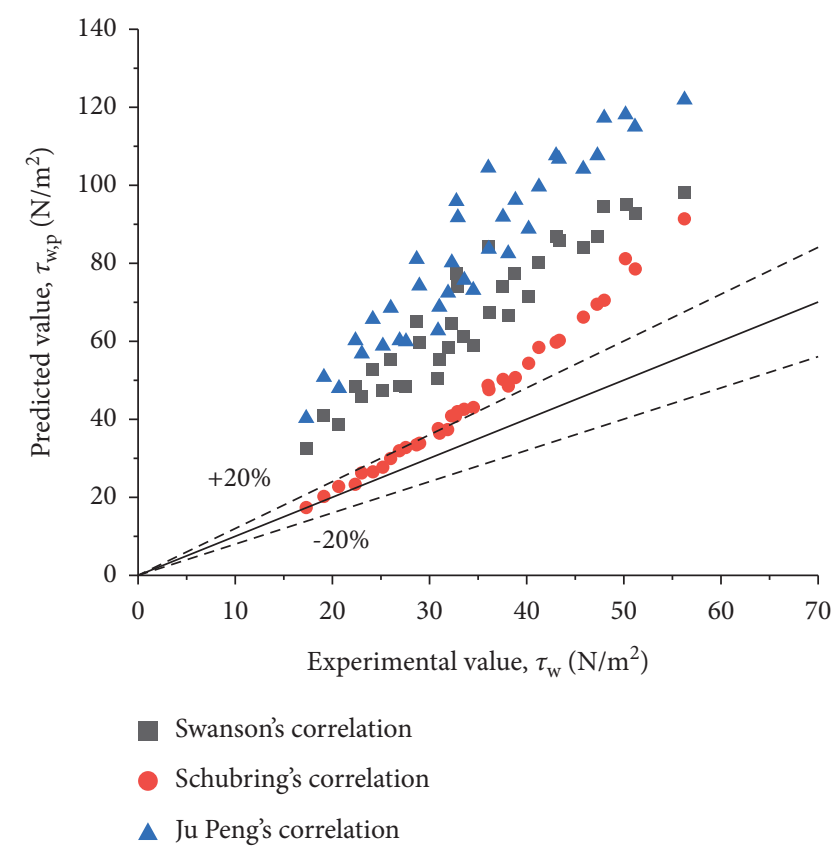

FIGURE 12: Wall shear stress relative error between correlation predicted results and experimental value.

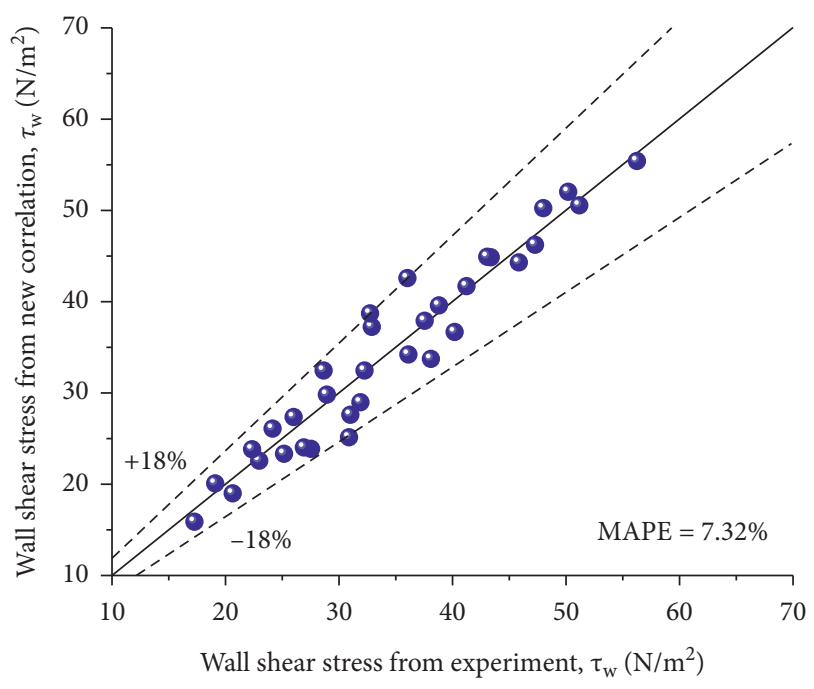

FIGURE 13: Comparison of the predicted values of the new relationship with the current experimental results.

phase flow rate. This indicates that the existing correlation of wall shear stress is not applicable to narrow channels. Equations (10) and (11) indicate that the shear force varies with the square of the velocity of the disturbed wave; that is, the disturbance wave provides a source of the shear force. In addition, droplet entrainment will become more and more serious with increasing gas phase velocity, so it is inappropriate to continue to use constant gas phase density because the droplets dispersed in the gas core will change the density of gas phase. Also, equation (4) indicates that the shear force depends on the density of the gas phase and the liquid phase. Therefore, the velocity of the disturbance wave, the density of the gas core, and the density of the liquid phase are connected to fit the new correlation by using the current experimental data:

$$
\tau_{w}=0.017 \sqrt{\rho_{c} \rho_{l}} v_{\mathrm{DW}}^{2} .
$$

Comparison of the predicted results of the new correlation with the current experimental value is shown in Figure 13. It can be seen from the figure that the new correlation can well predict the wall shear stress, all data are within the error band of $\pm 18 \%$, and MAPE is only $7.32 \%$.

\section{Conclusion}

In this paper, the disturbance wave velocity of annular flow in vertical narrow rectangular channel is studied by using high-speed photography technique. The existing prediction correlations of disturbance wave velocity were summarized and evaluated by using current experimental data. The results show that Ju Peng's correlation [5] can well predict the disturbance wave velocity of annular flow in vertical narrow rectangular channel. In addition, the wall shear stress of annular flow in a vertical narrow rectangular channel was calculated based on the simplified wall shear stress model, and a new correlation of wall shear stress was proposed.

\section{Nomenclature}

$\begin{array}{ll}A: & \text { Area } \\ D: & \text { Equivalent diameter } \\ e: & \text { Entrained liquid fraction } \\ e_{d}: & \text { Deposition liquid fraction } \\ g: & \text { Gravitational acceleration } \\ H: & \text { Duct thickness } \\ f: & \text { Frame } \\ j: & \text { Superficial velocity } \\ P: & \text { Perimeter } \\ t: & \text { Time } \\ \text { Re: } & \text { Reynolds number } \\ v: & \text { Velocity } \\ W: & \text { Duct width } \\ \text { We: } & \text { Weber number } \\ x: & \text { Mass gas quality. } \\ G r e e k & \text { symbols } \\ \delta: & \text { Thickness of liquid film } \\ \mu: & \text { Dynamic viscosity } \\ \rho: & \text { Density } \\ \tau_{i}: & \text { Interfacial shear stress } \\ \tau & \text { Wall shear stress. }\end{array}$

$$
\begin{array}{ll}
\text { Subscripts } \\
c: & \text { Core } \\
g: & \text { Gas phase } \\
i: & \text { Interfacial } \\
l: & \text { Liquid phase } \\
w: & \text { Wall }
\end{array}
$$

DW: Disturbance wave. 


\section{Data Availability}

The experimental data used to support the findings of this study are included within the article.

\section{Conflicts of Interest}

The authors declare that they have no conflicts of interest.

\section{Acknowledgments}

The authors greatly appreciate support from the National Key R\&D Program of China (2020YFB1901401) and Heilongjiang Provincial Key Laboratory of Nuclear Power System and Equipment, Harbin Engineering University, China.

\section{References}

[1] B. J. Azzopardi, "Disturbance wave frequencies, velocities and spacing in vertical annular two-phase flow," Nuclear Engineering and Design, vol. 92, no. 2, pp. 121-133, 1986.

[2] R. Kumar, M. Gottmann, and K. R. Sridhar, "Film thickness and wave velocity measurements in a vertical duct," Journal of Fluids Engineering, vol. 124, no. 3, pp. 634-642, 2002.

[3] D. Schubring, T. A. Shedd, and E. T. Hurlburt, "Studying disturbance waves in vertical annular flow with high-speed video," International Journal of Multiphase Flow, vol. 36, no. 5, pp. 385-396, 2010.

[4] C. Berna, A. Escrivá, J. L. Muñoz-Cobo, and L. E. Herranz, "Review of droplet entrainment in annular flow: interfacial waves and onset of entrainment," Progress in Nuclear Energy, vol. 74, pp. 14-43, 2014.

[5] P. Ju, Y. Liu, X. Yang, and M. Ishii, "Wave characteristics of vertical upward adiabatic annular flow in pipes," International Journal of Heat and Mass Transfer, vol. 145, Article ID 118701, 2019.

[6] C. Wang, N. Zhao, Y. Feng, H. Sun, and L. Fang, "Interfacial wave velocity of vertical gas-liquid annular flow at different system pressures," Experimental Thermal and Fluid Science, vol. 92, pp. 20-32, 2018.

[7] P. Ju, L. M. Pan, Y. Yan, Q. Zhu et al., "Predication of wall shear stress of vertical upward co-current adiabatic airwater annular flow in pipes," Nuclear Engineering and Design, vol. 368, Article ID 110797, 2020.

[8] R. Lin, K. Wang, L. Liu, Y. Zhang, and S. Dong, “Application of the image analysis on the investigation of disturbance waves in vertical upward annular two-phase flow," Experimental Thermal and Fluid Science, vol. 114, Article ID 110062, 2020.

[9] V. S. Chalgeri and J. H. Jeong, "Flow patterns of vertically upward and downward air-water two-phase flow in a narrow rectangular channel," International Journal of Heat and Mass Transfer, vol. 128, pp. 934-953, 2019.

[10] P. Sawant, M. Ishii, T. Hazuku, T. Takamasa, and M. Mori, "Properties of disturbance waves in vertical annular twophase flow," Nuclear Engineering and Design, vol. 238, no. 12, pp. 3528-3541, 2008.

[11] D. Schubring, Behavior interrelationships in annular flow, $\mathrm{PhD}$. thesis, University of Wisconsin-Madison, Madison, WI, USA, 2009.

[12] M. B. Alamu, Investigation of periodic structures in gas-liquid flow, PhD. thesis, University of Nottingham, Nottingham, England, 2010.
[13] P. Marmottant and E. Villermaux, "On spray formation," Journal of Fluid Mechanics, vol. 498, pp. 73-111, 2004.

[14] A. Al-Sarkhi, C. Sarica, and K. Magrini, "Inclination effects on wave characteristics in annular gas-liquid flows," AIChE Journal, vol. 58, no. 4, pp. 1018-1029, 2012.

[15] S. Levy, Two-Phase Flow in Complex Systems, John Wiley \& Sons Inc., New York, NY, USA, 1999.

[16] S. Wongwises and W. Kongkiatwanitch, "Interfacial friction factor in vertical upward gas-liquid annular two-phase flow," International Communications in Heat and Mass Transfer, vol. 28, no. 3, pp. 323-336, 2001.

[17] A. Cioncolini and J. R. Thome, "Entrained liquid fraction prediction in adiabatic and evaporating annular two-phase flow," Nuclear Engineering and Design, vol. 243, pp. 200-213, 2012.

[18] R.W. Swanson, Characteristics of the gas-liquid interface in two-phase annular flow, Ph.D. thesis, University of Delaware, Newark, DE, USA, 1966.

[19] D. Schubring and T. A. Shedd, "Prediction of wall shear for horizontal annular air-water flow," International Journal of Heat and Mass Transfer, vol. 52, no. 1-2, pp. 200-209, 2009. 